\title{
CORTICAL DESTRUCTION OF THE POSTERIOR PART OF THE BRAIN AND ITS EFFECT ON REASONING IN RATS ${ }^{1}$
}

\author{
NORMAN R. F. MAIER \\ Department of Psychology, University of Michigan \\ EIGHT TEXT FIGURES AND FOUR PLATES
}

\begin{tabular}{|c|c|}
\hline CONTENTS & \\
\hline Introduction & 180 \\
\hline Method and procedure & 180 \\
\hline a. Tests used ...... & 180 \\
\hline$\ldots \ldots \ldots \ldots \ldots \ldots \ldots \ldots \ldots \ldots \ldots$ & 182 \\
\hline c. Subjects & 183 \\
\hline 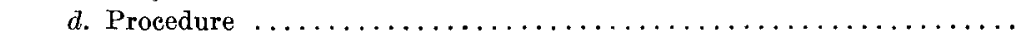 & 183 \\
\hline e. Operative and histological technique $\ldots \ldots \ldots \ldots \ldots \ldots$ & 184 \\
\hline Results & 184 \\
\hline a. Individual scores made by rats before and after operation ... & 184 \\
\hline$b$, Reliability of tests $\ldots \ldots \ldots \ldots \ldots \ldots \ldots \ldots \ldots \ldots$ & 186 \\
\hline c. Chance scores $\ldots \ldots \ldots \ldots \ldots \ldots \ldots \ldots \ldots \ldots$ & 187 \\
\hline$d$. The effect of peripheral blindness on test scores $\ldots \ldots \ldots \ldots \ldots$ & 188 \\
\hline $\begin{array}{r}\text { e. The effect of the destruction of the area for pattern vision on test } \\
\text { scores } \ldots \ldots \ldots \ldots \ldots \ldots \ldots \ldots \ldots \ldots \ldots \ldots \ldots \ldots \ldots\end{array}$ & 190 \\
\hline$f$. The effect of subeortical injuries on test scores $\ldots \ldots \ldots \ldots \ldots$ & 194 \\
\hline 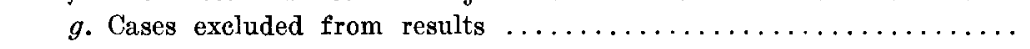 & 195 \\
\hline $\begin{array}{c}h . \text { The function of cortical tissue in the anterior and posterior parts } \\
\text { of the brain in reasoning } \ldots \ldots \ldots \ldots \ldots \ldots \ldots \ldots \ldots \ldots\end{array}$ & 196 \\
\hline 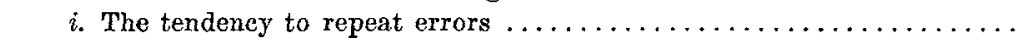 & 201 \\
\hline 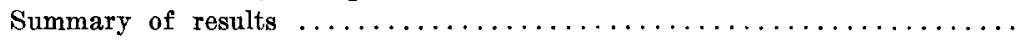 & 203 \\
\hline iscussion of results ....... & 204 \\
\hline onclusions $\ldots \ldots \ldots \ldots \ldots$. & 207 \\
\hline
\end{tabular}

${ }^{1}$ This study was carried on while the author was a National Research Council Fellow at The University of Chicago. The Otho S. A. Sprague Memorial Institute supplied the necessary materials for the investigation. Dr. K. S. Lashley sponsored the work and gave the author invaluable suggestions. Prof. C. J. Herrick, through his discussions with the author, was both suggestive and stimulating. Profs. Lashley and John F. Shepard read and criticized the manuscript. To all of these the author is greatly indebted.

179

THE JOURNAL OF COMPARATIVE NEUROLOGY, VOL. 56, NO. 1 


\section{INTRODUCTION}

Reasoning, defined as the ability to spontaneously combine the essentials of two or more isolated experiences, has been discussed in detail elsewhere $(5,6,7)$. The results of the study on the effect of cortical destruction on reasoning and learning in $\operatorname{rats}(7)$ showed that certain lesions which destroyed reasoning ability (when defined as above) did not affect learning ability when defined as the ability to combine two contiguous experiences. Further, it was found that the extent of the ability to pass the reasoning tests used showed a close correspondence with the amount of intact cortical tissue. This correspondence was such that lesions involving more than 18 per cent of the cortex in the anterior part of the brain completely destroyed the ability to pass the tests. Thus, there is a critical mass which is necessary in order for the rat to pass the tests used. The problem which now presents itself is whether this critical mass is the same for all parts of the cortex.

The present study is concerned with finding the critical amount of cortex which must be destroyed in the posterior part of the brain of the rat in order to destroy its ability to pass the same tests.

\section{METHOD AND PROCEDURE}

\section{a. Tests used}

The reasoning test (test $R$ ) used in the study of the function of the anterior part of the brain(7) was used in this study. That this test measures the ability to combine spontaneously the essentials of the two isolated experiences has already been demonstrated $(5,6,7)$. The test may be deseribed as follows:

From a point in the center of a large room three elevated pathways are placed to form three equal angles $\left(120^{\circ}\right.$ each). Tables are then placed at the ends of each of the pathways (fig. 1). The tables differ from each other in that they occupy different positions in the room, are of varying shapes 
and sizes, and have dissimilar tops. The pathways also form different angles with the edges of each table. Wooden screens $(s 1, s 2$, and $s 3)$ are placed at the inside edges of each table in order to obstruct any view from one table to another. Small holes ( 3 inches square) are cut in the screens over the pathways to form entrances to the tables.

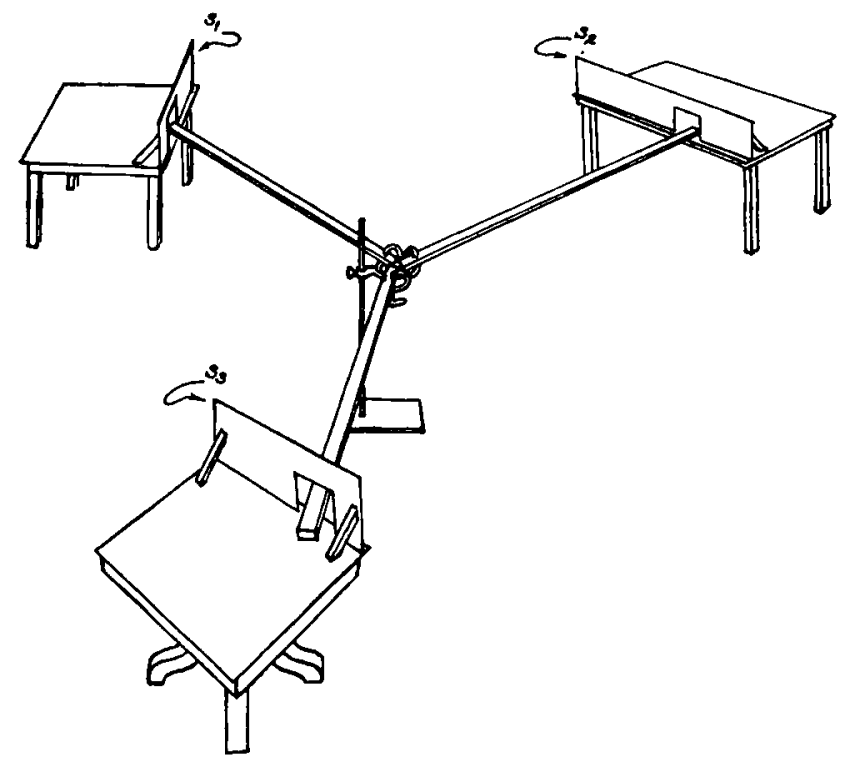

Fig. 1 Perspective drawing, showing apparatus used for testing reasoning ability. The pathways are 8 feet long and the small tables vary in size, shape, and character. $S 1, S 2$, and $S S$ are wooden screens placed on the tables to obstruct vision from one table to another.

By permitting a rat to explore this structure it is made familiar with all parts of the tables and pathways. The total group of experiences that the rat gains through this exploration I have called experience 1. (Tame rats unaccustomed to running on narrow pathways require about seven preliminary one-hour periods of exploration before they become thoroughly accustomed to running on the narrow pathways and familiar with all parts of the apparatus.)

After this period of exploration, food is placed on one of the tables. The rat is then placed on the same table and 
permitted to eat a small amount of food. It is then removed. I have called the experience of receiving food on one of the tables experience 2 .

The test consists of placing the animal on one of the other two tables and observing whether it can go directly to the food table. If it takes the direct route from the starting table to the food table, the run is correct. If it runs to the third table, the run is incorrect.

On the following day a brief period of exploration is again given. In this way, the animal may learn that no food is to be found on any of the tables. After this period of exploration the rat is fed on a table other than where food was presented on the previous day's trials (experience 2). It is then removed and placed on a different starting table for the test run.

By using different combinations of tables for the food table and the starting table on different days, the tests can be repeated indefinitely. (Six different combinations are possible and these may be used in order as many times as desired.)

In this study six preliminary tests were given in order to accustom the rats to the procedure. The actual testing period consisted of fifteen tests made on fifteen different days. After each group of six tests, one day of rest was given to reduce the effect of satiation. (It has been found( 8 ) that repeated testing produced inattention on the part of the rat. A rest period from time to time greatly reduced the tendency toward inattention.) The actual test period thus extended over a period of seventeen days.

\section{b. Scoring of tests}

In order that a rat be regarded as having passed the group of tests, it had to make twice as many correct as incorrect runs. Thus, in this case ten of the fifteen test runs had to be correct. In calculating the percentage of correct responses the difference between the number of correct and incorrect runs is divided by the number of tests runs. In this manner 
a chance score is reduced to 0 per cent and the lowest passing score at 33.3 per cent.

\section{c. Subjects}

Adult rats (ranging from 120 to 200 days in age) were used as subjects. The operative group consisted of fifty-eight rats. Eight of these died from the effects of the operation, the brain of one became infected from the operation, and one rat refused to run after the operation. Of the remaining forty-eight rats, eleven were male albinos, twelve male pigmented, fourteen female albino, and eleven female pigmented. A control group consisted of fourteen rats, four of which were male albino, two male pigmented, seven female albino, and one female pigmented. A blinded group of rats consisted of ten rats, four of which were male albino, one male pigmented, two female albino, and three female pigmented.

The scores made by these groups of rats (all tested before operation), when classified according to sex and coloring, are as follows:

$$
\begin{array}{ll}
\text { Male albino, } & 77.6 \text { per cent (19 eases) } \\
\text { Male pigmented, } & 83.1 \text { per cent (15 eases) } \\
\text { Female albino, } & 84.4 \text { per cent ( } 23 \text { cases) } \\
\text { Female pigmented, } & 89.3 \text { per cent ( } 15 \text { cases) }
\end{array}
$$

These differences in score are so small in comparison with the differences on which our conclusions are to be based that sex and coloration may be disregarded as factors determining the score of a group of rats.

\section{d. Procedure}

In order to study the effect of cortical lesions on reasoning ability, each rat was put through the group of tests before operation and again after recovery from the operation. Fourteen days were allowed for recovery. In some cases two test periods were given after operation with two weeks' interval between the groups of tests. No improvement was shown by rats in the second postoperative group of tests, so the two weeks allowed for recovery were sufficient. 
The reliability of the tests was measured by having a parallel group of normal rats take the tests during the same two test periods that the operated rats were being tested. If two such test periods showed the same results, any difference in scores made by rats tested before and after operation must be considered as due to the effects of the operation.

The effect of lesions in the posterior part of the brain was controlled by studying the performance of a group of blinded rats in the same tests.

Further details regarding procedure will be given when the results are presented.

\section{e. Operative and histological technique}

Rats were partially decorticated under deep ether anaesthesia by means of thermocautery. Peripheral blindness was produced by the enucleation of the eyes. The technique used for the calculation of the extent of cortical destruction is that devised by Lashley and has been described by him in detail(2).

\section{RESULTS}

\section{a. Individual scores made by rats before and after operation}

The results of the test made on rats subjected to cortical lesion in the posterior part of the brain are given in table 1. Column 1 gives the experimental number, sex, and coloring of the animals. ( $\mathrm{M}$ and $\mathrm{F}$ indicate male and female, respectively, $\mathrm{A}$ and $\mathrm{P}$ indicate albino and pigmented, respectively). The second column gives the percentage of cortical surface destroyed. Columns 3 and 4 give the number of correct and incorrect test runs made by each rat before operation, and columns 5 and 6 give the number of correct and incorrect test runs made after operation. The last column indicates whether a rat failed $(\mathrm{F})$ or passed $(\mathrm{P})$ the tests.

The lesions suffered by each rat are represented diagrammatically in plates $1,2,3$, and 4 .

Table 1 shows that before operation the animals made an average of 83.6 per cent correct responses, or 13.8 out of 
TABLE 1

Scores made by rats before and after cortical injury

\begin{tabular}{|c|c|c|c|c|c|c|}
\hline \multirow{2}{*}{ RAT } & \multirow{2}{*}{$\begin{array}{l}\text { PFR OENT OF } \\
\text { DEBTRUO- } \\
\text { TION }\end{array}$} & \multicolumn{2}{|c|}{$\begin{array}{l}\text { SOORE BETORE } \\
\text { OPERATION }\end{array}$} & \multicolumn{2}{|c|}{$\begin{array}{l}\text { SCORE AFTFER } \\
\text { OPERATION }\end{array}$} & \multirow{2}{*}{$\begin{array}{c}\text { TESTS } \\
\text { PABBED } \\
\text { OR FAILED } \\
\text { (P OB W) }\end{array}$} \\
\hline & & Correct & Incorrect & Correct & Incorrect & \\
\hline $1 \mathrm{FP}$ & 9.8 & 15 & 0 & 15 & 0 & $\mathbf{P}$ \\
\hline $2 \mathrm{MP}$ & 9.8 & 15 & 0 & 15 & 0 & $\mathbf{P}$ \\
\hline $3 F A$ & 10.4 & 15 & 0 & 11 & 4 & $\mathrm{P}$ \\
\hline $4 \mathrm{FA}$ & 10.8 & 14 & 1 & 12 & 3 & $\mathbf{P}$ \\
\hline $5 \mathrm{FA}$ & 11.0 & 15 & 0 & 13 & 2 & $\mathrm{P}$ \\
\hline $6 \mathrm{FA}$ & 11.7 & 14 & 1 & 14 & 1 & $\mathbf{P}$ \\
\hline $7 \mathrm{MP}$ & 12.8 & 13 & 2 & 13 & $\overline{2}$ & $\overline{\mathbf{P}}$ \\
\hline $8 \mathrm{FA}$ & 13.2 & 12 & 3 & 10 & 5 & $\mathbf{P}$ \\
\hline $9 \mathrm{MP}$ & 14.0 & 14 & 1 & 15 & 0 & $\mathbf{P}$ \\
\hline $10 \mathrm{MP}$ & 14.5 & 13 & 2 & 13 & 2 & $\mathbf{P}$ \\
\hline $11 \mathrm{MA}$ & 16.8 & 15 & 0 & 12 & 3 & $P$ \\
\hline $12 \mathrm{MA}$ & 17.7 & 11 & 4 & 11 & 4 & $\mathrm{P}$ \\
\hline $13 \mathrm{FA}$ & 18.1 & 14 & 1 & 13 & 2 & $\mathbf{P}$ \\
\hline $14 \mathrm{FP}$ & 18.3 & 14 & 1 & 15 & 0 & $P$ \\
\hline $15 \mathrm{MP}$ & 18.5 & 15 & 0 & 12 & 3 & $\mathbf{P}$ \\
\hline $16 \mathrm{MA}$ & 18.5 & 14 & 1 & 13 & 2 & $\mathbf{P}$ \\
\hline $17 \mathrm{MA}$ & 18.9 & 15 & 0 & 13 & 2 & $\bar{P}$ \\
\hline 18FP & 19.1 & 14 & 1 & 15 & 0 & $\mathbf{P}$ \\
\hline $19 \mathrm{MP}$ & 20.0 & 14 & 1 & 12 & 3 & $\mathbf{P}$ \\
\hline 20FA & 20.4 & 12 & 3 & 13 & 2 & $\mathbf{P}$ \\
\hline $21 \mathrm{MP}$ & 20.8 & 13 & 2 & 13 & 2 & $\mathbf{P}$ \\
\hline $22 \mathrm{FP}$ & 21.1 & 14 & 1 & 11 & 4 & $\mathbf{P}$ \\
\hline 23FP & 21.3 & 15 & 0 & 13 & 2 & $\mathrm{P}$ \\
\hline $24 \mathrm{MP}$ & 21.3 & 12 & 3 & 12 & 3 & $\mathbf{P}$ \\
\hline $25 \mathrm{MA}$ & 21.9 & 14 & 1 & 14 & 1 & $\mathbf{P}$ \\
\hline $26 F P$ & 21.9 & 13 & 2 & 8 & 7 & $\mathbf{F}$ \\
\hline $27 \mathrm{MP}$ & 22.1 & 15 & 0 & 14 & 1 & $\mathbf{P}$ \\
\hline $28 \mathrm{MA}$ & 22.1 & 12 & 3 & 14 & 1 & $\mathbf{P}$ \\
\hline $29 \mathrm{MP}$ & 22.3 & 14 & 1 & 13 & 2 & $\mathbf{P}$ \\
\hline 30FA & 22.3 & 15 & 0 & 4 & 11 & $\mathbf{E}$ \\
\hline 31FA & 22.7 & 14 & 1 & 11 & 4 & $\mathbf{P}$ \\
\hline $32 \mathrm{FP}$ & 22.8 & 15 & 0 & 9 & 6 & $\mathbf{F}$ \\
\hline $33 \mathrm{MP}$ & 23.0 & 15 & 0 & 8 & 7 & $\mathbf{F}$ \\
\hline $34 \mathrm{FA}$ & 23.4 & 13 & 2 & 7 & 8 & $\mathbf{F}$ \\
\hline $35 \mathrm{FA}$ & 23.4 & 13 & 2 & 9 & 6 & $\mathrm{~F}$ \\
\hline $36 \mathrm{MA}$ & 23.4 & 11 & 4 & 8 & 7 & $\mathbf{F}$ \\
\hline $37 \mathrm{FP}$ & 24.0 & 14 & 1 & 6 & 9 & $\mathbf{F}$ \\
\hline 38FP & 24.2 & 13 & 2 & 9 & 6 & $\mathbf{F}$ \\
\hline $39 \mathrm{FA}$ & 24.5 & 15 & 0 & 6 & 9 & $\mathbf{F}$ \\
\hline $40 \mathrm{MA}$ & 24.9 & 12 & 3 & 6 & 9 & $\mathbf{F}$ \\
\hline $41 \mathrm{MA}$ & 25.1 & 13 & 2 & 9 & 6 & $\mathbf{F}$ \\
\hline $42 \mathrm{MA}$ & 25.5 & 12 & $\mathbf{3}$ & 8 & 7 & $\mathbf{F}$ \\
\hline $43 \mathrm{MA}$ & 25.7 & 14 & 1 & 4 & 11 & $\mathbf{F}$ \\
\hline $44 \mathrm{FA}$ & 25.8 & 13 & 2 & 9 & 6 & $\mathbf{F}$ \\
\hline $45 \mathrm{MP}$ & 26.2 & 14 & 1 & 8 & 7 & $\mathbf{F}$ \\
\hline $46 \mathrm{FA}$ & 30.9 & 15 & 0 & 6 & 9 & $\mathrm{~F}$ \\
\hline $47 \mathrm{FP}$ & 31.5 & 15 & 0 & 9 & 6 & $\mathbf{F}$ \\
\hline $48 \mathrm{FP}$ & 37.2 & 15 & 0 & 8 & 7 & $\mathbf{F}$ \\
\hline Average & 20.53 & $\begin{array}{l}13.77 \\
83.6 \%\end{array}$ & 1.23 & $\begin{array}{r}10.75 \\
43.5 \%\end{array}$ & 4.25 & \\
\hline
\end{tabular}

Column I gives the experimental number, the sex, and the coloring of the animals. ( $\mathbf{M}$ and $\mathbf{F}$ indicate male and female, respectively. $\mathbf{A}$ and $\mathbf{P}$ indicate albino and pigmented, respectively.) Column 2 gives the percentage of cortical surface destroyed. Columns 3 and 4 give the number of correct and incorrect test runs made before operation, and column 5 and 6 give the same data for runs made after operation. The last column indicates whether a rat failed (F) or passed (P) the tests. (Failure to pass the tests is indicated when less than ten of the fifteen test runs are correct.) 
15 trials correct. In contrast to this the average of the animals after operation is $43: 5$ per cent correct, or 10.8 correct in 15 trials. Moreover, it is clear from the table that the poorer average after operation is a result of the failure of the animals with the larger lesions. The critical point for effectiveness of the lesion is about 22.7 per cent. No animal with a lesion larger than this passed the criterion of ten or more correct runs and, with the exception of rats 26 and 30 , all animals with lesions less than 22.8 per cent passed the criterion. These two exceptional cases are close to the border line with lesions of 21.9 per cent and 22.3 per cent.

The average percentage of correct responses for animals with lesions less than 22.8 per cent is 66.5 ; that for animals with lesions more than 22.7 per cent is only 1.2. Thus, although there is some reduction in efficiency in the case of the rats with the smaller lesions, their scores are well above chance. In contrast to this, the scores of the animals with larger lesions are on the average almost exactly what should be expected from pure chance. The results seem conclusive in favor of the view that there is a critical extent of destruction which abolishes the function involved in the test.

\section{b. Reliability of tests}

A comparison of the scores made by animals before and after operation is only justified when the measuring instrument remains relatively constant. In order to test the reliability of repeated testing as well as the accuracy of the tests, fourteen normal rats were put through the group of fifteen tests at three different times. An interval of two weeks was given between the test periods.

Table 2 gives the scores made by these rats in the three different test periods. In the first test period they made 80 per cent correct responses; in the second, 81 per cent, and in the third, 78.1 per cent. Thus, even with this small group of rats the variation in the score in the three test periods was never as great as 3 per cent. We may therefore conclude that the difference in score made by rats before and after operation was due to the effects of the operation. 


\section{c. Chance scores}

As any individual test may be run correctly by chance, it is of interest to know just what score a group of rats will make when dependent only upon chance. Ordinarily, the rats reached the food by combining experiences 1 and 2 . If one of these experiences is not given to the rat, it cannot combine two experiences and so can reach the food only by

TABLE 2

Scores made by normal rats in three different test periods

\begin{tabular}{|c|c|c|c|c|c|c|}
\hline \multirow[b]{2}{*}{ RAT } & \multicolumn{2}{|c|}{ FIRST TEST PHRIOD } & \multicolumn{2}{|c|}{ SECOND TEST PERIOD } & \multicolumn{2}{|c|}{ THIRD TEST PERIOD } \\
\hline & $\begin{array}{c}\text { Correct } \\
\text { runs }\end{array}$ & $\begin{array}{l}\text { Incorrect } \\
\text { runs }\end{array}$ & $\begin{array}{l}\text { Correct } \\
\text { runs }\end{array}$ & $\begin{array}{l}\text { Incorrect } \\
\text { runs }\end{array}$ & $\begin{array}{l}\text { Correct } \\
\text { runs }\end{array}$ & $\begin{array}{l}\text { Incorrect } \\
\text { runs }\end{array}$ \\
\hline $101 \mathrm{MA}$ & 14 & 1 & 13 & 2 & 34 & 1 \\
\hline 102MA & 14 & 1 & 13 & 2 & 11 & 4 \\
\hline $103 \mathrm{MA}$ & 15 & 0 & 13 & 2 & 14 & 1 \\
\hline $104 \mathrm{MA}$ & 12 & 3 & 12 & 3 & 12 & 3 \\
\hline $105 \mathrm{MP}$ & 12 & 3 & 15 & 0 & 15 & 0 \\
\hline $106 \mathrm{MP}$ & 12 & $\mathbf{3}$ & 13 & 2 & 12 & 3 \\
\hline $107 \mathrm{FA}$ & 15 & 0 & 14 & 1 & 13 & 2 \\
\hline $108 \mathrm{FA}$ & 15 & 0 & 15 & 0 & 15 & 0 \\
\hline $109 \mathrm{FA}$ & 14 & 1 & 13 & 2 & 14 & 1 \\
\hline $110 \mathrm{FA}$ & 14 & 1 & 14 & 1 & 13 & 2 \\
\hline $111 \mathrm{FA}$ & 12 & 3 & 14 & 1 & 11 & 4 \\
\hline $112 \mathrm{FA}$ & 14 & 1 & 14 & 1 & 15 & 0 \\
\hline $113 \mathrm{FA}$ & 12 & 3 & 14 & 1 & 14 & 1 \\
\hline \multirow[t]{2}{*}{$114 \mathbf{F P}$} & 14 & 1 & 13 & 2 & 14 & 1 \\
\hline & $\begin{array}{c}13.50 \\
80.0 \%\end{array}$ & 1.50 & $\begin{array}{c}13.57 \\
81.0 \%\end{array}$ & 1.43 & $\begin{array}{c}13.36 \\
78.1 \%\end{array}$ & 1.64 \\
\hline
\end{tabular}

This table shows the number of eorrect and incorrect runs made by normal rats in three different test periods. There was an interval of two weeks between each test period.

'trial and error.' In testing for a chance score, experience 2 was therefore omitted. In every other respect, however, the procedure remained the same. The rats were given a period of exploration (experience 1) as usual. They were then removed and carried to one of the tables on which food was placed. The rats were, however, not placed on the table and permitted to eat. For the test run they were placed on the starting table as usual. Thus the procedure for these rats 
was the same as for all the others except that they were not placed on the food table for a bite of food.

Table 3 shows the average score for rats tested under chance conditions to be -17.7 per cent. Thus, as a group, they made more incorrect than correct runs. Further, none of the rats reached the criterion of ten correct out of fifteen test runs.

Thus it is obvious that neither chance, smell, nor vision was sufficient to enable the previous group of rats to make high scores.

TABLE 3

Scores made by rats when experience 2 is omitted

\begin{tabular}{|c|c|c|c|c|c|}
\hline RAT & $\begin{array}{l}\text { CORRECT } \\
\text { RUNG }\end{array}$ & $\begin{array}{l}\text { INCORREOT } \\
\text { RUNS }\end{array}$ & $\mathbf{R A T}$ & $\begin{array}{c}\text { CORRECT } \\
\text { RUNS }\end{array}$ & $\begin{array}{l}\text { INCORRECT } \\
\text { RUNS }\end{array}$ \\
\hline $115 \mathrm{MA}$ & 7 & 8 & $123 \mathrm{FA}$ & 5 & 10 \\
\hline $116 \mathrm{MA}$ & 7 & 8 & $124 \mathrm{FA}$ & 8 & 7 \\
\hline $117 \mathrm{MA}$ & 7 & 8 & $125 \mathrm{FA}$ & 2 & 13 \\
\hline 118MA & 5 & 10 & $126 \mathrm{FA}$ & 7 & 8 \\
\hline $119 \mathrm{MA}$ & 6 & 9 & & -- & -- \\
\hline $120 \mathrm{MA}$ & 7 & 8 & Average & 6.17 & 8.83 \\
\hline $121 \mathrm{FP}$ & 6 & 9 & & $-17.7 \%$ & \\
\hline $122 \mathrm{FP}$ & 7 & 8 & & & \\
\hline
\end{tabular}

This table shows the number of correct and incorrect runs made by normal rats when the solution depended on chance. One experience was excluded and the ability to combine two experiences could therefore not function.

\section{d. The effect of peripheral blindness on test scores}

As lesions in the posterior part of the brain may produce visual disturbances, it is important that the part played by vision in the performance of the tests be analyzed. Consequently, ten rats were tested before and after having their eyes enucleated.

It was found that all rats passed the tests before being. blinded. The tests given after recovery from the operation showed that six of the rats failed to pass the tests, whereas the other four passed the tests with high scores.

Observation of the behavior of the blinded rats showed that their orientation was poor and their hunger drive very weak (e.g., they would leave the food when placed before it in experience 2 ). 
To improve the first of these conditions boards were nailed sidewise on the tables so as to give them added tactual characteristics. (Previously the tables differed only in size and shape.)

The hunger drive was increased by testing the rats on the morning of one day, the afternoon of the next, giving them a vacation on the third day, testing them on the morning of the fourth, etc. After each test the rats were given as much food as they desired. This procedure was more satisfactory than underfeeding, because weakness resulting from underfeeding was also avoided.

When tested under these modified conditions, nine of the ten rats passed the tests.

Rats with cortical lesions were also tested under these modified conditions, but none of the rats which failed the tests under the previous conditions passed them under the modified conditions.

Table 4 gives the individual scores of the blinded group of rats in the preoperative tests and in the two groups of postoperative tests. Table 5 gives the same for a group of rats with cortical lesions which were tested at the same time and under the same conditions.

From table 4 it is seen that the modified conditions raise the scores of the blinded rats from 33.3 per cent correct to 62.7 per cent correct. But from table 5 it is seen that the same modified conditions show a reduction in score from 20.8 per cent correct to 7.5 per cent correct in the case of rats with cortical lesions. It is therefore obvious that the low scores made by rats with cortical lesions are due to a different cause than the low scores made by peripherally blinded rats. The blind rats were able to combine two isolated experiences when the experiences given had enough characteristics to make them distinguishable from others, but the partially decorticated rats with lesions in the visual areas failed to take advantage of these cues. Since there is no reason to believe that the majority of the animals suffered from sensory defects other than visual, we can only ascribe their failure to an inability to combine the essentials of two isolated experiences. 
e. The effect of destruction of the area for pattern vision on the test scores

According to Lashley(4), the critical area for pattern vision is in the lateral part of field $w$ of Fortuyn (fig. 2). If the loss of pattern vision interfered with the rat's performance in the tests, then rats having lesions largely destroying this critical area should show a greater tendency to fail the tests than rats with lesions in other areas.

TABLE 4

Scores made by blind rats

\begin{tabular}{|c|c|c|c|c|c|c|}
\hline \multirow{2}{*}{ RAT } & \multicolumn{2}{|c|}{ BEFORE OPGRATION } & \multicolumn{2}{|c|}{ AFTER OPERATION } & \multicolumn{2}{|c|}{$\begin{array}{c}\text { MODIYIED TEST } \\
\text { OONDITIONS }\end{array}$} \\
\hline & Correct & Incorrect & Correct & Incorrect & Correct & Incorrect \\
\hline $201 \mathrm{MA}$ & 15 & 0 & 14 & 1 & 14 & 1 \\
\hline $202 \mathrm{MA}$ & 13 & 2 & 8 & 7 & 12 & 3 \\
\hline $203 \mathrm{MA}$ & 14 & 1 & 14 & 1 & 14 & 1 \\
\hline 204MA & 13 & 2 & 13 & 2 & 13 & 2 \\
\hline $205 \mathrm{MP}$ & 15 & 0 & 14 & 1 & 14 & 1 \\
\hline $206 \mathrm{FP}$ & 13 & 2 & 9 & 6 & 11 & 4 \\
\hline $207 \mathrm{FP}$ & 14 & 1 & 6 & 9 & 11 & 4 \\
\hline $208 \mathrm{FP}$ & 15 & 0 & 9 & 6 & 9 & 6 \\
\hline $209 \mathrm{FA}$ & 13 & 2 & 7 & 8 & 14 & 1 \\
\hline $210 \mathrm{FA}$ & 15 & 0 & 6 & 9 & 10 & 5 \\
\hline & - & - & 一 & - & - & $\longrightarrow$ \\
\hline Average & $\begin{array}{c}14 \\
86.7 \%\end{array}$ & 1 & $\begin{array}{c}10 \\
33.3 \%\end{array}$ & 5 & $\begin{array}{r}12.2 \\
62.7 \%\end{array}$ & 2.8 \\
\hline
\end{tabular}

This table shows the number of correct runs made by the blinded group of rats during three test periods. The first group of tests was given before the animals were blinded, the second and third after they were blinded. The third test period differs from the second in that additional characteristics were added to the tables, and the motivation of the rats was more thoroughly controlled.

In table 6 the rats are divided into three groups as follows: 1) those with lesions which include two-thirds or more of the critical area on both hemispheres; 2) those with lesions which include one-third or less of the critical area on both hemispheres; and, 3) all rats with lesions which do not fall in the other two divisions.

This table shows that, a) of the twenty-two rats failing in the first division, seventeen passed the tests and only five 
TABLE 5

Scores made by rats with cortical lesions when tested under the same conditions as blind rats

\begin{tabular}{|c|c|c|c|c|c|c|}
\hline \multirow{2}{*}{$\mathbf{R A T}$} & \multicolumn{2}{|c|}{ BEFORE OPERATION } & \multicolumn{2}{|c|}{ AFTER OPERATION } & \multicolumn{2}{|c|}{$\begin{array}{l}\text { MODIEIED TEST } \\
\text { CONDITIONS }\end{array}$} \\
\hline & Correct & Incorrect & Correct & Incorrect & Correct & Incorrect \\
\hline 3FA & 15 & 0 & 11 & 4 & 12 & 3 \\
\hline $6 \mathrm{FA}$ & 14 & 1 & 14 & 1 & 11 & 4 \\
\hline $17 \mathrm{MA}$ & 15 & 0 & 13 & 2 & 12 & $\mathbf{3}$ \\
\hline $18 \mathrm{FP}$ & 14 & 1 & 15 & 0 & 14 & 1 \\
\hline 25MA & 14 & 1 & 14 & 1 & 12 & 3 \\
\hline $26 \mathrm{FP}^{1}$ & 13 & 2 & 8 & 7 & 8 & 7 \\
\hline $30 \mathrm{FA}$ & 15 & 0 & 4 & 11 & 6 & 9 \\
\hline $32 \mathrm{FP}$ & 15 & $\mathbf{0}$ & 8 & 7 & 6 & 9 \\
\hline $34 \mathrm{FA}^{1}$ & 13 & 2 & 7 & 8 & 7 & 8 \\
\hline $36 \mathrm{MA}$ & 11 & 4 & 8 & 7 & 5 & 10 \\
\hline $37 \mathrm{FP}$ & 14 & 1 & 6 & 9 & 7 & 8 \\
\hline $38 \mathrm{FP}$ & 13 & 2 & 9 & 6 & 5 & 10 \\
\hline $39 \mathrm{FA}$ & 15 & 0 & 6 & 9 & 7 & 8 \\
\hline $41 \mathrm{MA}$ & 13 & 2 & 9 & 6 & 7 & 8 \\
\hline $42 \mathrm{MA}^{1}$ & 12 & 3 & 8 & 7 & 8 & 7 \\
\hline $46 \mathrm{FA}$ & 15 & 0 & 6 & 9 & 5 & 10 \\
\hline $48 \mathrm{FP}^{1}$ & 15 & 0 & 8 & 7 & 5 & 10 \\
\hline Average & $\begin{array}{l}13.88 \\
85.1 \%\end{array}$ & 1.12 & $\begin{array}{r}9.06 \\
20.8 \% \\
\end{array}$ & 5.94 & $\begin{array}{r}8.06 \\
7.5 \% \\
\end{array}$ & 6.94 \\
\hline
\end{tabular}

This table gives the same data as table 4, except that in this case the data are from rats with cortical lesions in the posterior part of the brain.

1 The four rats indicated showed slight motor defects which were only detectable when the rats ran on the narrow pathways. The defect consisted of a tendency to lose footing with the hind legs. A few days of practice on the pathways eliminated this, and only a very slight stiffness seemed to remain. The four rats all had area $n$ (of Fortuyn) completely destroyed and areas $f^{\prime}$ and $f$ partially destroyed. The only other rat having injuries in the above three motor areas was ease no. 30 and it had very slight injuries in areas $f^{\prime}$ and $f$. (See pls. 1, 2, 3, and 4.)

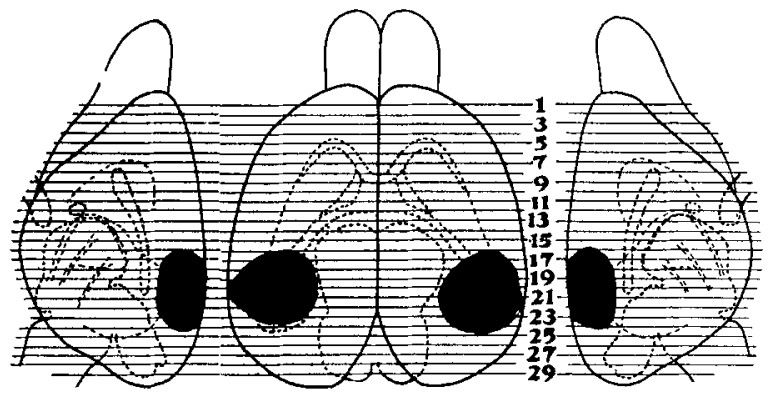

Fig. 2 Figure 2 shows the critical area which Lashley has found to be essential for normal pattern vision. 
failed; b) of the two rats in the second division, one passed the tests and one failed; and, c) of the twenty-four rats in the third division, eleven passed the tests and thirteen failed.

Thus it is obvious that rats having the critical area for pattern vision destroyed are no more handicapped in their performance in these tests than rats with lesions less extensive in this area.

\section{TABLE 6}

Rats classified according to lesions in the visual area

\begin{tabular}{|c|c|c|}
\hline & RATS WHIOH PASSED TESTS & RATS WHIOH FAILAED TEBTE \\
\hline $\begin{array}{l}\text { Cases involving two-thirds } \\
\text { or more of visual area } \\
\text { on both hemispheres }\end{array}$ & $\begin{array}{l}2,5,7,13,14,15,16,17, \\
18,19,23,24,25,27,28, \\
29, \text { and } 31\end{array}$ & $35,38,40,46$, and 48 \\
\hline Total number of cases & 17 rats & 5 rats \\
\hline $\begin{array}{l}\text { Cases involving one-third } \\
\text { or less of visual area } \\
\text { on both hemispheres }\end{array}$ & 10 & 26 \\
\hline Total number of eases & 1 rat & 1 rat \\
\hline Remaining cases & $\begin{array}{c}1,3,4,6,8,9,11,12 \\
20,21, \text { and } 22\end{array}$ & $\begin{array}{c}30,32,33,34,36,37 \\
39,41,42,43,44,45 \\
\text { and } 47\end{array}$ \\
\hline Total number of cases & 11 rats & 13 rats \\
\hline
\end{tabular}

In this table the rats which passed and those which failed the tests are classifled into three groups according to the extent that their lesions invaded the critical area for pattern vision.

Rats which had been tested for pattern vision were also given the reasoning tests. ${ }^{2}$ It was found that out of thirtyone rats tested for pattern vision after suffering lesions in the posterior part of the brain, ten showed decided visual disturbances. These ten rats made 52 per cent correct responses on the reasoning tests, whereas the remaining twenty-one rats with normal pattern vision made 58.7 per cent correct responses.

${ }^{2}$ Dr. Margaret Frank, who is studying pattern vision in rats in Doctor Lashley's laboratory, kindly permitted me to use her rats as well as her data for my study. 
This difference in score is very slight and consequently the possible loss of pattern vision due to operation cannot be used to explain the results obtained.

The data given above eliminate visual defects of any kind arising from lesions in the posterior part of the brain as an explanation of the results. There remains the question of other sensory defects.

a. Olfactory. Cues of an olfactory nature might be important in orientation or in the recognition of the tables. Olfactory defects, if produced by these lesions, must be due to the invasion of olfactory structures, i.e., the hippocampal structures. In the following section (section $\mathfrak{f}$ ) it will be shown that lesions in these structures had no influence on the results. The results obtained from the 'chance' group of rats (section c) clearly show that food odor was not a cue for the rats.

b. Auditory. Shepard(9) has shown that an auditory cue is often utilized by rats in maze learning. It is difficult to see how such cues might be effective in the present situation, where a correct run is required on the first trip. Wiley(11) has delimited the auditory area as corresponding to Fortuyn's area $p$, and he has found auditory defects only with extensive destruction within this area. No case in this series involved a destruction of area $p$ great enough to produce a significant disturbance in auditory discrimination and many animals which failed had no invasion of area $\mathrm{p}$.

c. Somesthetic and motor. In the study on the effect of cortical destruction in the anterior part of the brain the somesthetic (area j) and motor (areas f, $f^{\prime}$, and $n$ ) fields were largely involved. In the present study many cases which failed the tests showed no injury to area $j$, and only injury to the hind leg and tail areas of $f, f^{\prime}$, and $n$. Yet the effect of posterior and anterior cortical lesions is not greatly different, as will be shown later (section $\mathrm{h}$ ). Thus we have lesions of similar extent which either greatly involve the somesthetic and motor areas or which involve these areas slightly or not at all, but which, nevertheless, give similar 
results in their performance of the tests. This indicates that the deprivation of the major senses likely to be concerned in orientation do not account for the failure of the operated rats.

Such differences as appeared between the rats with anterior and posterior lesions indicate a greater effect of somesthetic and motor-area destruction than lesions in the visual area. Since sensory components in these tests (as is not true in the maze) must function chiefly as a means for recognizing a given environment (food table and starting table) somesthesis would necessarily play a minor rôle. Motor defects, on the other hand, would play no part in such recognition, and would only affect running. No rats with lesions in the motor area were handicapped in their running by the lesions.

Thus a theory of sense privation does not conform with the results. There remains only the possibility that the function of reasoning is disturbed by the lesions.

\section{f. The effect of subcortical injuries on test scores}

The hippocampus was the only subcortical structure injured. It was slightly injured in a large number of cases. If injury to the hippocampus influences the test scores, then it follows that failures should appear among rats with large hippocampal injuries and small cortical injuries.

In table 7 the rats are classified into three groups according to the extent of injury to the hippocampus. The divisions are as follows: a) no injury in subcortical centers; b) slight injuries to the hippocampus; and c) larger injuries to the hippocampus.

Inspection of the table shows that both successes and failures appear in all divisions. Further, all failures appearing among the group of rats with larger hippocampal injuries suffered cortical lesions which were greater in extent than the critical lesions ( 22.8 per cent). (Rats numbered 32 to 48 suffered lesions from 22.8 per cent to 37.2 per cent.) The only rats which failed the tests and had cortical injuries less extensive than 22.7 per cent were rats 26 and 30 . Rat 26 had 
but a very slight injury to the hippocampus and rat 30 had no injury to the hippocampus.

Thus it appears that injuries in the subcortical centers do not account for any of the failures in the tests.

\section{g. Cases excluded from results}

Data from the following numbers of rats are not included in the results:

Eight rats died from the effects of the operation. Before operation they made 81.7 per cent correct responses.

TABLE 7

\begin{tabular}{|c|c|c|}
\hline & RATS WHIOH PASSED TESTS & RATS WHIOH FAILED TESTS \\
\hline No subcortical injury & $\begin{array}{c}2,3,4,6,7,9,10,15 \\
20,27, \text { and } 28\end{array}$ & 30 and 45 \\
\hline $\begin{array}{l}\text { Slight injury to hippo- } \\
\text { campus }\end{array}$ & $\begin{array}{c}1,5,8,11,12,13,16,17 \\
18,21,22,29, \text { and } 31\end{array}$ & $\begin{array}{c}26,33,34,35,40 \\
42, \text { and } 43\end{array}$ \\
\hline $\begin{array}{l}\text { Larger injury to hippo- } \\
\text { campus }\end{array}$ & $14,19,23,24$, and 25 & $\begin{array}{c}32,36,37,38,39,41 \\
44,46,47, \text { and } 48\end{array}$ \\
\hline
\end{tabular}

In this table the rats which passed and those which failed the tests are classified according to the extent of injuries to subcortical structures. Rats numbered 1 to 31 had lesions less extensive than 22.8 per cent; those with numbers above 31 had lesions more extensive than 22.7 per cent.

Two rats failed the tests as normal rats and were therefore not studied.

One rat refused to run because of having been frightened, and was therefore dropped.

One rat (49) refused to run after operation. Its lesion was 17.5 per cent in extent.

One rat (50) had a brain infection which was discovered at autopsy. The infection completely destroyed a large amount of subcortical tissue. The rat failed the tests after operation; 19.5 per cent of the cortex was injured. 


\section{h. The function of cortical tissue in the anterior and posterior parts of the brain in reasoning}

Having shown that the mass of cortical tissue destroyed alone explains the results obtained, we may proceed to a further analysis of the data.

In table 8 the rats are classified according to the extent of injury. The divisions are as follows: 1) 0 per cent detruction; 2) 9 to 15 per cent destruction; 3) 16 to 20 per cent destruction;4) 21 to 22 per cent destruction; 5) 23 to 24 per cent destruction; 6) 25 to 37 per cent destruction. The

TABLE 8

The effect of cortical destruction in the posterior part of the brain on reasoning ability

\begin{tabular}{|c|c|c|c|c|c|}
\hline \multirow[b]{2}{*}{ LESION } & \multirow{2}{*}{$\begin{array}{l}\text { NUMBER } \\
\text { OW CASES }\end{array}$} & \multirow{2}{*}{$\begin{array}{l}\text { REASONING } \\
\text { BEFORF } \\
\text { OPERATION }\end{array}$} & \multirow{2}{*}{$\begin{array}{c}\text { SCORE } \\
\text { AFTER } \\
\text { OPERATION }\end{array}$} & \multicolumn{2}{|c|}{ RATS PASSING TESTS } \\
\hline & & & & $\begin{array}{c}\text { Before } \\
\text { operation }\end{array}$ & $\underset{\text { operation }}{\text { After }}$ \\
\hline Per.cent & & Per-cent & Per-cent & Per-cent & Per-cent \\
\hline 0 & 13 & 80.0 & 81.0 & 100 & 100 \\
\hline $9-15$ & 10 & 86.7 & 75.7 & 100 & 100 \\
\hline $16-20$ & 11 & 83.0 & 72.1 & 100 & 100 \\
\hline $21-22$ & 11 & 85.5 & 49.2 & 100 & 72.7 \\
\hline $23-24$ & 8 & 76.7 & -1.7 & 100 & 00 \\
\hline $25-37$ & 8 & 85.0 & 1.7 & 100 & 00 \\
\hline
\end{tabular}

In this table the rats are grouped according to the sizes of their lesions. The last four columns show the percentage of correct responses made before and after operation, and the percentage of rats in each of the groups which passed the tests before and after operation.

scores made before and after operation, as well as the percentage of rats passing the tests before and after operation, are given for each group.

Figures 3, 4, 5, 6, and 7 show the combined extent of the lesions for the last five groups. In figures 3,4 , and 5 the posterior half of the brain is well explored, yet these three groups only include three rats which failed the tests. Figure 8 gives the combined extent of the lesions suffered by the rats which passed the tests. This figure shows the lesions of these rats to be well distributed over the posterior part of the brain. The lateral aspects of the brain, however, remained unexplored. 

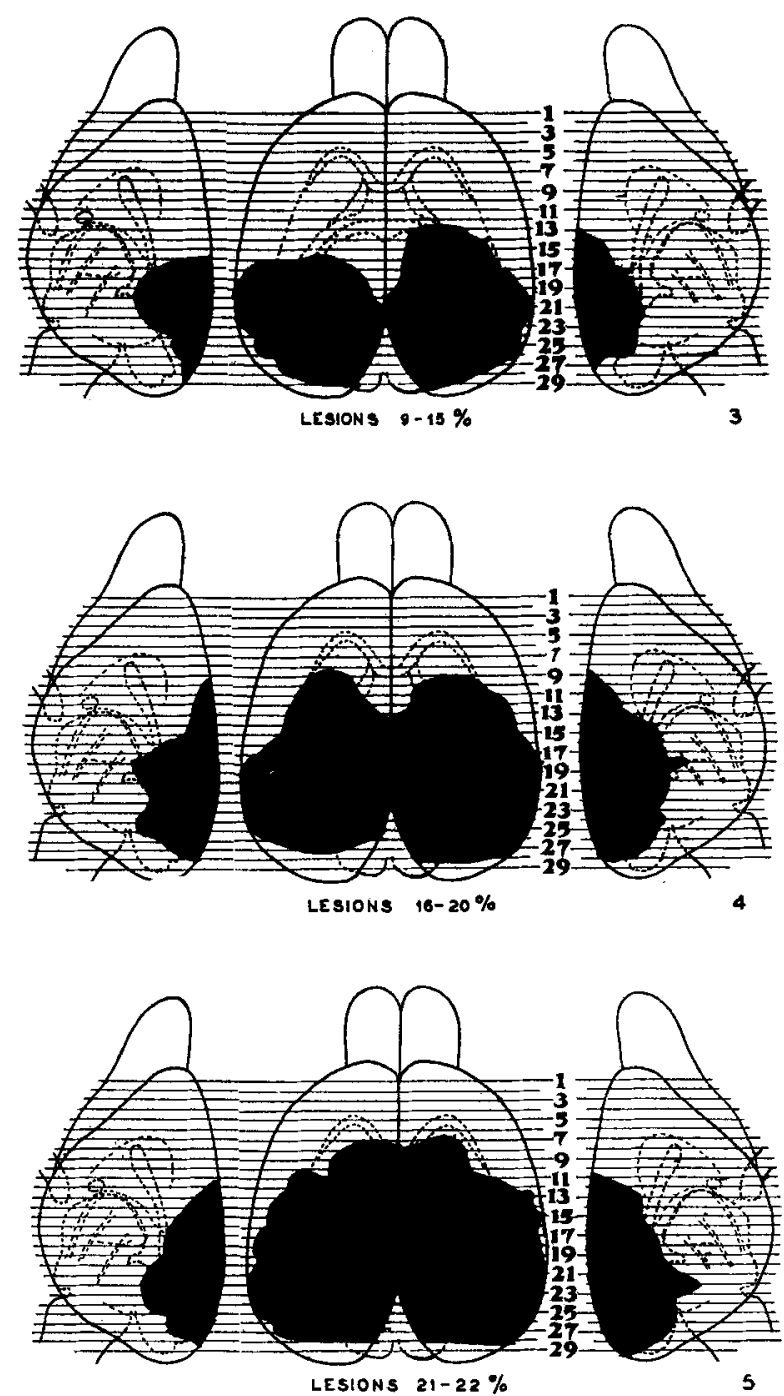

Figs. 3, 4, 5, 6, 7, and 8 Figures 3, 4, 5, 6, and 7 show the combined extent of the lesions of the rats which are grouped according to the extent of injury to the cortex. Figure 8 gives the combined extent of the lesions of all rats which passed the tests. 
Inspection of table 8 shows that the test scores gradually fall off as the extent of the lesions increase up to 23 per cent. At this point, however, the test scores suddenly drop to a chance value. Table 1 shows the eritical lesion to be 22.8 per cent.
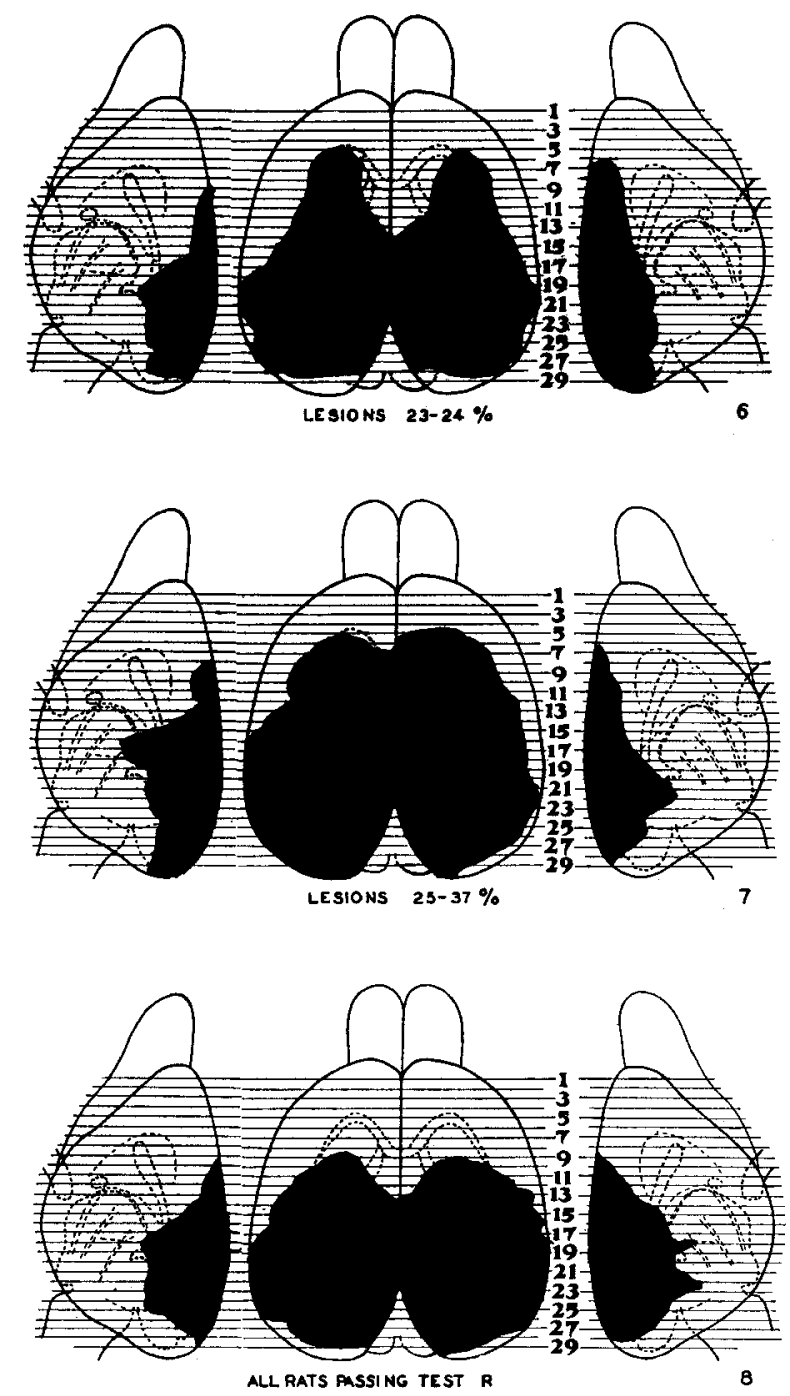
A study of the effect of cortical lesions in the anterior part of the brain(7) revealed very similar results. Table 9 reproduces the results of this investigation.

A comparison of tables 8 and 9 shows that in both cases there is a gradual falling off in score with an increase in the extent of the lesions and a sudden drop in score when the lesions exceed a certain critical amount. The results, however, differ in that in the case of the anterior part of the brain the critical lesion is 18 per cent, whereas in the case of the posterior part of the brain it is 22.8 per cent.

That a difference in the critical masses of the anterior and posterior parts of the brain may be present is further supported by the fact that lesions less than 18 per cent in extent

TABLE 9

The effect of cortioal destruction in the anterior part of the brain on reasoning ability $(\gamma)$

\begin{tabular}{c|c|c|c}
\hline LESION & $\begin{array}{c}\text { NUMBER OF } \\
\text { CASES }\end{array}$ & $\begin{array}{c}\text { REASONING SOORE } \\
\text { AFTER OPERATION }\end{array}$ & $\begin{array}{c}\text { RATS PASSING } \\
\text { TESTS }\end{array}$ \\
\hline Per cent & & Percent & Per cent \\
0 & 19 & 80.7 & 100 \\
$1-10$ & 4 & 63.9 & 100 \\
$11-17$ & 9 & 43.2 & 66.7 \\
$18-24$ & 8 & 8.3 & 25.0 \\
$25-41$ & 11 & 1.1 & 18.2 \\
\hline
\end{tabular}

This table summarizes the results of the earlier study on the effect of lesions in the anterior part of the brain on reasoning ability.

reduce the scores of rats with frontal lesions to a greater extent than rats with posterior lesions.

Further, if we examine the lesions of rats 26 and 30 (pl. 3 ) which failed the tests, but had lesions less than 22.8 per cent in extent (21.9 per cent and 22.3 per cent, respectively), we find that the location of the lesion of rat 26 was largely in the anterior part of the brain and the lesion of rat 30 was more forward than other lesions of nearly the same size.

These cases do not demonstrate that there is a definite mass of cortical tissue which when destroyed eliminates the ability to pass the tests; they merely favor the view that cortex in the posterior part of the brain is slightly less important for reasoning than cortex in the anterior part of the brain. 
As the difference in the critical masses is less than 5 per cent, the existence of an actual difference in potentiality may be seriously questioned for two reasons:

1. The region between 18 per cent and 22.8 per cent may not have been adequately explored and the critical masses would consequently only be approximations.

2. There may be a constant error in the calculations of the lesions which causes such a difference to appear.

The first objection may be met as follows:

The present study included nineteen cases with lesions between 18 per cent and 22.8 per cent in extent. Of these, seventeen rats passed the tests and two failed. The study on the anterior part of the brain included five cases within this range. Of these one rat passed the tests and four failed. Thus many of the cases have fallen within this critical range, but the success or failure of the cases seems to depend on whether the lesions were anterior or posterior.

The second objection, however, cannot be definitely met at the present time. The technique for determining the extent of the lesions depends on projecting them onto a chart of the average rat's brain. If this chart is proportionally smaller in the anterior than in the posterior part, all lesions projected on the anterior part will be diminished. Consequently, the same sized lesions when measured will show a smaller percentage of the whole brain if anterior than if posterior.

On the other hand, if the chart is proportionately larger in the anterior than in the posterior part, then all anterior lesions will be exaggerated and will thus be found to be larger than they actually are. If this is the case, the difference in the critical mass of anterior and posterior lesions is actually greater than we have found it to be.

Lashley, ${ }^{3}$ who devised the brain charts as well as the technique for reconstructing the lesions, is of the opinion that if a source of error is present it is because the anterior part of the brain chart is proportionally too large. It has also been my experience in projecting brains on the charts to find them

\footnotetext{
${ }^{3}$ From a written communieation.
} 
slightly out of proportion because of the broadness of the anterior part.

If these impressions are true, the constant error is such as to make the actual difference in the critical masses larger than we have found it to be, rather than to account for it. But this by no means settles the itssue. It is obvious, however, that we have reached a point where a more refined technique is necessary. To settle the question measurements must be based on the reconstructions of the proportions of each brain.

\section{$i$. The tendency to repeat errors}

The rats were required to make two trips from the starting point to food after each of the fifteen test runs. The purpose of this was to test the tendency of the rats to repeat erroneous runs. Thus if a rat ran incorrectly on a test run and also on one or both of the two following runs, it showed a tendency toward stereotyped behavior. If it ran correctly on the test run and incorrectly on one or both of the two following runs, it indicated one or more of the following conditions: a) inadequate hunger motivation; b) a tendency toward variable behavior; and, c) inability to profit by the experience of a correct run.

In table 10 the tendency to make 0 errors, 1 error, or 2 errors in the two runs following correct and incorrect test runs is shown for all groups of rats. The data for rats with 0 per cent lesions are taken from rats listed in table 1 ; those for the operated rats are taken from their postoperative tests; and those for the blind rats are taken from tests made under modified conditions (see p. 189).

Table 10 shows that the tendency to repeat the error made on a test run gradually increases with an increase in the extent of injury to the cortex until the lesion approaches 23 per cent. At this point the tendency to repeat erroneous test runs becomes very great. Thus the group with 21 to 22 per cent lesions only repeat an erroneous test run in both of the following two runs in 9.5 per cent of the cases, but the 
group with 23 to 24 per cent lesions repeat such an error 54.1 per cent of the time. Thus rats with lesions smaller than 23 per cent very seldom repeat an error on two successive runs, but rats with larger lesions successively repeat such errors more than half of the time.

That the erroneous runs following incorrect test runs are actually repetitions of the error made in the test run is obvious when we consider the small number of errors made after a correct test run. The greatest number of times that any group made errors on the two runs following a correct test run was 8.5 per cent.

TABLE 10

The tendency to repeat errors

\begin{tabular}{|c|c|c|c|c|c|c|c|}
\hline \multirow{2}{*}{ LESION } & \multirow{2}{*}{$\begin{array}{l}\text { NUMBER } \\
\text { OF RATS }\end{array}$} & \multicolumn{3}{|c|}{$\begin{array}{l}\text { CORRECT TEST RUN } \\
\text { FOLTOWED BY }\end{array}$} & \multicolumn{3}{|c|}{$\begin{array}{l}\text { INCORRECT TEST RUN } \\
\text { FOLLOWED BY }\end{array}$} \\
\hline & & $\begin{array}{c}\text { 0 error } \\
\text { runs }\end{array}$ & $\begin{array}{c}1 \text { error } \\
\text { runs }\end{array}$ & $\begin{array}{l}2 \text { error } \\
\text { runs }\end{array}$ & $\begin{array}{c}0 \text { error } \\
\text { runs }\end{array}$ & $\begin{array}{c}1 \text { error } \\
\text { runs }\end{array}$ & $\begin{array}{l}2 \text { error } \\
\text { runs }\end{array}$ \\
\hline Per cent & & Per cent & Per cent & Per cent & Per cent & Per cent & Per cent \\
\hline 0 & 14 & 98.9 & 1.1 & 0 & 100 & 0 & 0 \\
\hline $9-15$ & 10 & 98.5 & 1.5 & 0 & 78.9 & 21.1 & 5.3 \\
\hline $16-20$ & 11 & 94.4 & 5.6 & 0 & 69.6 & 30.4 & 4.3 \\
\hline $21-22$ & 11 & 95.9 & 4.1 & 0 & 66.7 & 33.3 & 9.5 \\
\hline $23-24$ & 8 & 78.0 & 22.0 & 8.5 & 18.0 & 82.0 & 54.1 \\
\hline $25-37$ & 8 & 72.1 & 27.9 & 8.2 & 23.7 & 76.3 & 62.7 \\
\hline Blind & 10 & 82.8 & 17.2 & 1.6 & 60.7 & 39.3 & 25.0 \\
\hline Chance & 12 & 86.5 & 13.5 & 1.4 & 73.6 & 26.4 & 1.9 \\
\hline
\end{tabular}

This table shows the responses of different groups of rats in the two runs follawing both correct and incorrect test runs. Of these two runs, neither, or one, or both may be wrong. The percentages of times that each of these conditions is found are shown in separate columns.

Rats with larger lesions, however, make errors in one of the two runs following a correct test run in more than 20 per cent of the cases, whereas the rats with lesions smaller than 23 per cent make such errors less than 6 per cent of the time. This indicates that extensive lesions produce a certain amount of unstability or random activity.

Blind rats, although they showed ability to pass the tests, demonstrated nearly as great a variability in behavior as rats with lesions larger than 23 per cent. After a correct test run they made errors in one of the two following runs 
17.2 per cent of the time. However, they repeated incorrect test runs only about one-half as often as rats with the larger lesions. The tendency toward stereotyped behavior is only great when the tendency to make errors after an incorrect test run is much greater than the tendency to make errors after correct test runs. As this difference is not great in the case of the blind rats, their behavior can hardly be regarded as stereotyped. Rather it is unstable and variable.

The animals which found the food by chance on the test run rapidly learned the position of the food. Their tendency to repeat an incorrect test run on one of the following two runs was 26.4 per cent, but the tendency to repeat an error on both of the runs was only 1.9 per cent. In this respect they were superior to all of the operated rats.

However, their variability was greater than that of all rats with lesions less than 23 per cent in extent. They made an error after a correct test run 13.5 per cent of the time.

The results of table 10 may be summarized as follows:

1. The tendency toward stereotyped behavior increases as the ability to reason decreases.

2. An increase in stereotyped behavior is accompanied by a decrease in stability or an increase in random activity.

3. Blind rats show a great deal of variability and unstability in their behavior, yet their behavior is not stereotyped. In other words, it is difficult to predict what they will do on any particular run from their performance on previous runs.

4. Rats which find the food by chance in the test run do nearly as well on the following runs as normal rats not handicapped in this manner.

\section{SUMMARY OF RESULTS}

The results of this study may be summarized as follows:

1. Destruction of cortical tissue in the posterior part of the brain, like destruction of cortical tissue in the anterior part of the brain, reduces a rat's ability to pass the reasoning tests. 
2. The ability to pass the tests is not dependent on any particular area of the brain, but rather depends on the amount of the intact tissue.

3. For both the anterior and posterior parts of the brain there is a definite critical mass of cortical tissue which when destroyed results in the sudden falling off in reasoning ability.

4. This critical mass is about 18 per cent of the entire cortical surface in the anterior part of the brain and 22.8 per cent in the posterior part of the brain. In other words, 18 per cent of cortical tissue in the anterior part of the brain seems equal to 22.8 per cent cortical tissue in the posterior part of the brain as far as ability to pass the reasoning tests is concerned. The possibility of a constant error in measurement being responsible for this difference is discussed.

5. Although sensory projection areas are destroyed by cortical lesions, their reduction in no way explains the results obtained.

6. Reduction in the ability to pass the reasoning tests is accompanied by stereotyped behavior and greater random activity.

7. The lateral aspects of the brain alone were left unexplored in this and an earlier study (7).

\section{DISCUSSION OF RESULTS}

Lashley has shown(2) that there is a marked correlation between maze-learning ability and the amount of intact cortical tissue. His study excluded any interpretation based on a specific localization of such an ability. He also showed(3) that the sensory defects resulting from the destruction of cortical sensory areas, which Hunter(1) has stressed, in no way explained his results.

The results of this study as well as of the previous one show a close relationship between cortical mass and reasoning ability. Further, as in the case of maze-learning ability, the ability to combine the essentials of two isolated experiences has no specific locus in any part of the cortex. The 
destruction of sufficient cortical tissue affects a rat's performance in the tests in much the same way, whatever the locus of the lesion. Nor is the defect in performance due to any specific sensory or motor disturbance, but rather to an inability to combine the essentials of two isolated experiences.

The results, however, differ from those obtained in maze studies in that the destruction of a certain critical mass of cortical tissue completely destroys the animal's ability to pass the tests. Lesser destruction, on the other hand, affects the animal's performance but little. Thus there is a slight falling off in efficiency in the case of rats with small lesions; but when the lesions approach a certain critical size, there is a rapid drop to zero ability.

Reasoning ability and maze-learning ability thus seem to be qualitatively different in that the destruction of equal units of cortex does not cause corresponding disturbances in reasoning ability, but tends to do so in the case of mazelearning ability, as is indicated by the correlation between mass of brain tissue and learning ability. Thus the relationship between cortical mass and maze learning seems to be a continuous function, whereas the relationship between cortical mass and reasoning ability is either a discontinuous function or a continuous function in which there is a region of rapid change. To decide the nature of this relationship it is necessary to test animals on a graded series of tests with which varying degrees of ability can be measured.

A further difference between reasoning and maze-learning ability is the difference in the amount of cortical tissue which must be destroyed in order to produce profound defects in the rats' performance of them. Thus small lesions (23 per cent in extent) completely eliminate the rats' ability to pass the simple reasoning tests, whereas rats with extensive lesions (more than 50 per cent in extent) can still learn the maze (Lashley's maze III).

Thus maze learning and reasoning are alike in that they have no specific locus in the cortex, but depend on the mass of cortical tissue present. They differ in that the amount 
of destruction necessary to produce decided deterioration is less in the case of reasoning than in maze learning, and in that the curves of the relationship between cortical mass and the two abilities are different.

Lesions in the anterior and posterior parts of the cortical surface affect reasoning ability qualitatively in much the same way. In both cases there is a critical mass which, when destroyed, results in inability to pass the tests. Lesions less extensive, however, show little or no effects. There seems to be qualitative equipotentiality of the cortex for reasoning ability as well as for learning ability. On the other hand, there is evidence of a quantitative difference in potentiality for these two regions of the rat's brain. Thus the critical mass for eliminating the ability to pass the reasoning tests was 18 per cent in the anterior part of the brain and 22.8 per cent in the posterior part of the brain. The possibility of error is present in these measurements; but the indication is that such errors, if present, are of such character as to increase the apparent size of the critical mass in the anterior part of the brain and thus to minimize the difference. More refined techniques would therefore be more likely to increase the difference in the critical masses rather than to decrease it.

If this quantitative difference in the critical masses is verified, the cause of such a difference requires an explanation. It is possible that the variation in thickness of different parts of the cortex may account for the facts. According to the findings of Sugita(10), the cortex at the frontal pole is the thickest, and that at the occipital pole is the thinnest. As our critical masses are measures of the surface destroyed, it is possible an 18 per cent lesion in the anterior part of the brain is equal in volume to a 22.8 per cent lesion in the posterior part of the brain. Due to the fact that Sugita found a correlation between cortical volume and skin surface, it is not altogether unlikely that volume rather than surface should be measured. On the other hand, the phylogenetic studies of development indicate that surface rather than volume is important in the development of intelligent behavior. 
If the difference in the critical masses cannot be accounted for in terms of volume, the conclusion that a quantitative difference in potentiality actually exists, is indicated. Such a conclusion implies that the anterior part of the cortex is either richer in its associative connections or that it is less specialized and consequently more plastic in function than the posterior part of the brain. The solution of this problem must be left to the neurologist.

\section{CONCLUSIONS}

1. A study of cortical destruction of the posterior part of the brain and its effect on the reasoning ability in rats confirms the results of the study of the function of cortex in the anterior part of the brain.

2. Small lesions to any part of the cortex have little effect on reasoning ability. Lesions larger than a certain critical mass completely eliminate the ability to pass the tests.

3. Mass rather than locus determines what the effect of a lesion will be, but there is no evidence of a continuous function in the sense that lesions of increasing size show proportionately greater effect. Rather the effect of the lesion seems to be more nearly of an 'all-or-nothing' character. In this respect the relationship between cortical mass and reasoning ability differs from that between cortical mass and mazelearning ability.

4. Further evidence of a qualitative distinction between reasoning and learning ability is thus brought out.

5. A comparison of the effects of cortical lesions in the anterior and posterior parts of the brain indicates that for reasoning these two parts of the brain are qualitatively equipotential, but quantitatively unequal in potentiality.

\section{LITERATURE CITED}

1 HUNTER, W. S. 1930 A consideration of Lashley's theory of the equipotentiality of cerebral action. J. Gen. Psych., vol. 3, pp. 455-468.

2 LAShley, K. S. 1929 Brain mechanisma and intelligence. Univ. of Chieago Press. pp. 3-20. 
4 LASHLEY, K. S. 1931 The mechanism of vision. IV. The cerebral areas necessary for pattern vision in the rat. J. Comp. Neur., vol. 53, pp. $419-478$.

5 MaIfr, N. R. F. 1929 Reasoning in white rats. Comp. Psych. Mono., vol. 6, pp. 1-93.

6 1931 Reasoning and learning. Psych. Review, vol. 38, pp. 332-346.

7 - 1932 The effect of cortical destruction on reasoning and learning in rats. J. Comp. Neur., vol. 54, pp. 45-75.

$8-1930$ Attention and iuattention in rats. J. Genet. Psych., vol. $38, \mathrm{pp} .288-306$.

9 Shepard, J. F. 1926 An unexpected cue in maze learning. Psych. Bull., vol. 26, p. 164 .

1931 More learning. Psych. Bull., vol. 28, p. 240.

10 Sugita, N. 1918 Comparative studies on the growth of the cerebral cortex. VIII. General review of data for the thickness of the cerebral cortex and the size of the cortical cells in several mammals, together with some postnatal growth changes in these structures. J. Comp. Neur., vol. 29, pp. 241-278.

11 WILEY, L. E. 1932 The function of the brain in aduition. J. Comp. Neur., vol. 54, pp. 109-141. 
PLATES 


\section{PLATES 1 TO 4}

The following plates diagrammatically represent the extent and location of the cortical tissue destroyed in each rat's brain. 

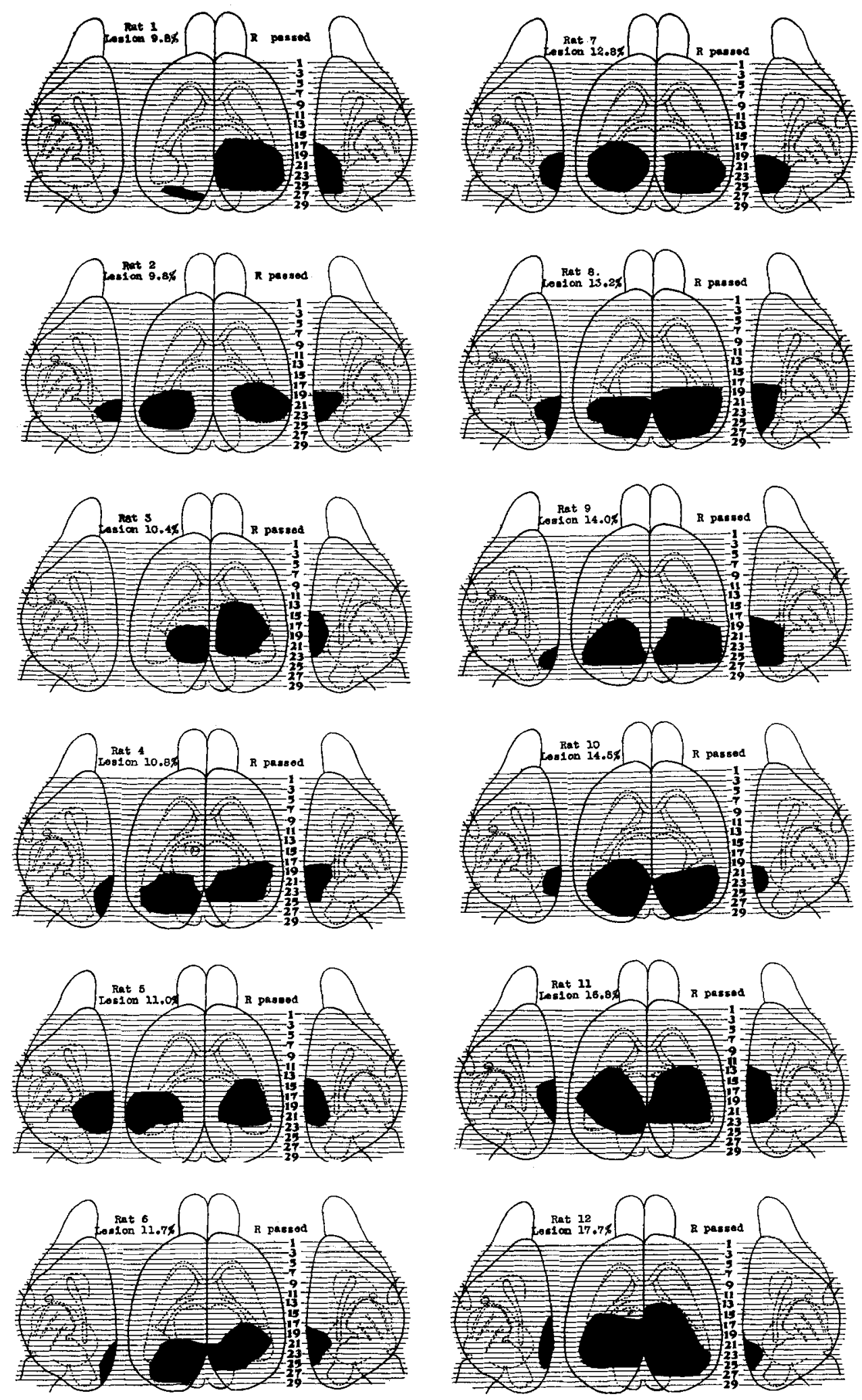
NORMAN R. F. MAIEE
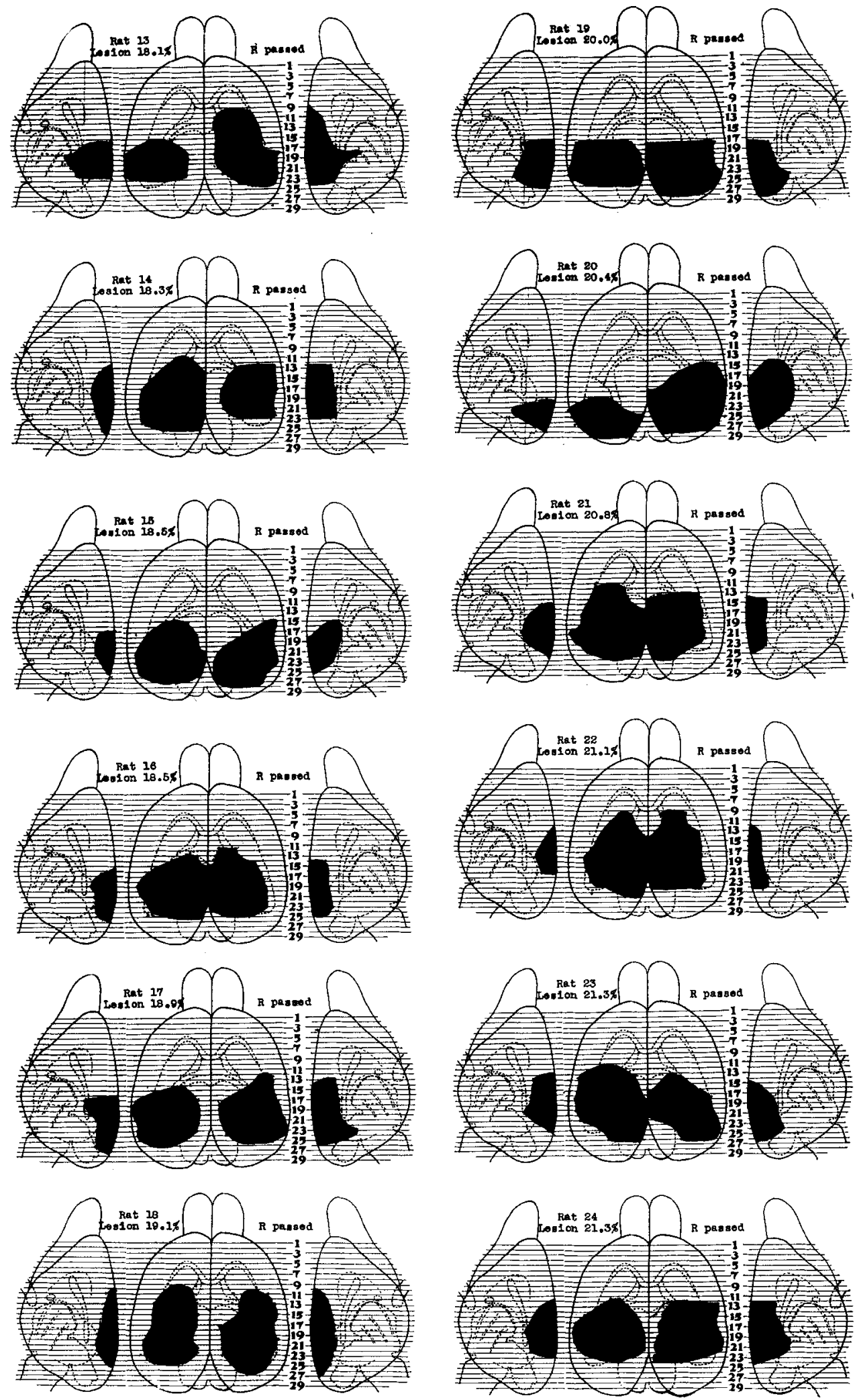

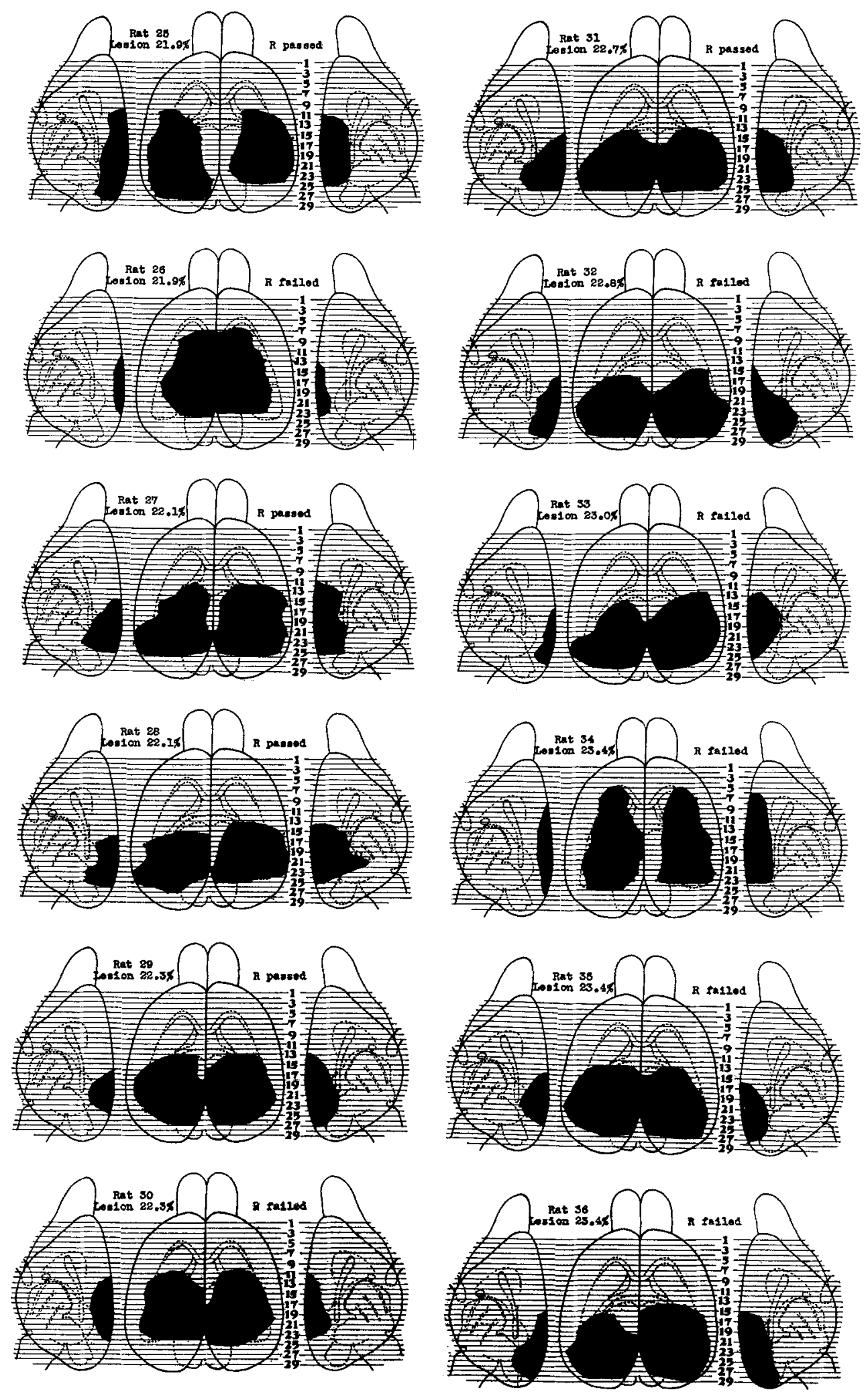

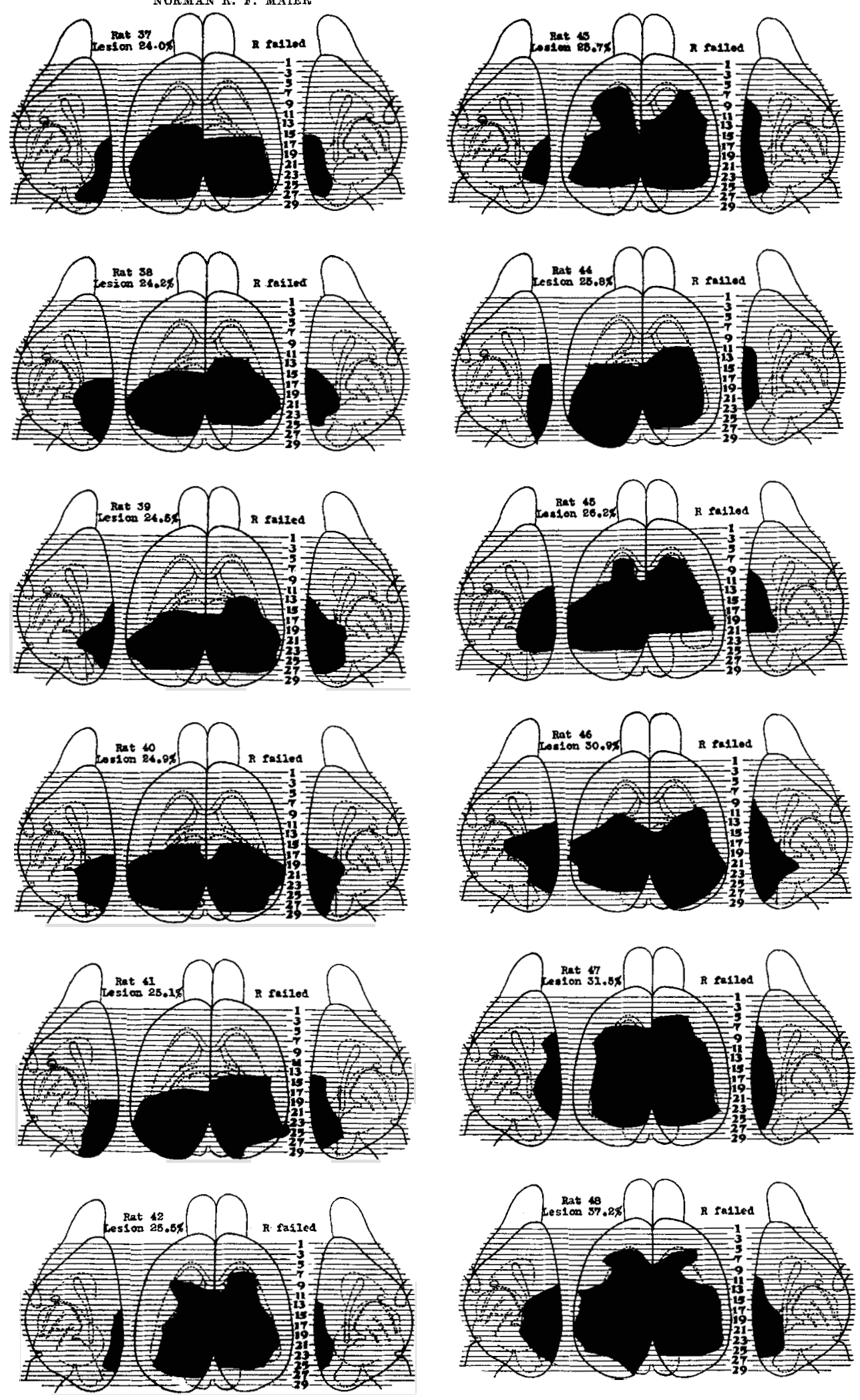